\title{
The association between Type 2 diabetes with obstructive sleep apnea in extremely obese subjects in Algazera area in Sudan from Jan 2009 to Jan 2011
}

\author{
Article by Mashail Mohamed Fadol, Abdalmutaleb Mohamed \\ Master of Public Health, Texila American University, Sweden \\ Email: fmashail@hotmail.com
}

\section{Introduction}

Obstructive sleep apnea is common under-diagnosed disease associated with high incidence of cardiovascular disease and death there is a strong association between OSA and obesity, almost $70 \%$ of patients with OSA are obese. As Obesity and fat deposits may affect compliance of upper airway walls and lead to narrowing of luminal area, which increase the airway collapse

OSA is also there is strong relation between OSA and increased risk of type 2 diabetes by different mechanisms, like intermittent hypoxia, sleep disturbance and immune activation may affect this association. Which play important role in the pathogenesis

Central obesity, increase level of insulin and resistance are associated with high risk of OSA, some researches shown a high prevalence of T2DM and pre-diabetes in obese patient with OSA, which indicate cause glucose intolerance may cause by OSA.

Study aimed to assess whether extremely obese people who have T2DM and preDM have higher odds of OSA than their counterparts with normal glucose tolerance.

\section{Objectives}

To assess whether morbid obese individuals who has T2DM have higher risk of OSA than the normal glucose tolerance

\section{Methods}

One hundred consecutive extremely obese patients underwent somnography and a 2-hour oral glucose tolerance test (OGTT). OSA was defined as apnea-hypopnea index (AHI) of $\geq 15$ events/hour, resulting in two groups (OSA+ vs. OSA-)Patients were categorized into three groups according to criteria from the American Diabetes Association: normal glucose tolerance, pre-diabetes and type 2 diabetes. Multiple logistic regression analysis was used to identify possible determinants of OSA. This was a prospective observational study with the average age: 52 years; body mass index (BMI): 47.3(8.3) $\mathrm{kg} / \mathrm{m} 2)$

Data are given as either mean (SD) or proportions (\%) unless stated otherwise. Between group differences were assessed using independent samples t-test or analysis of variance

\section{Result}

The patients had a mean age of 52 years and assessed obesity by body mass index (BMI) of ): $47.3(8.3) \mathrm{kg} / \mathrm{m} 2$ ).the ratio of Males to female AHI was high, 29 to 12 events/hour, $\mathrm{p}<$ $0.001 .82 \%$ of men has OSA and in $58 \%$ of women observed, $\mathrm{p}=0.008$. normal glucose were found in Thirty-nine percent of subjects, 32\% were pre-diabetes and type 2 DM in $29 \%$. OSA were $35 \%$ Among the patients with normal glucose tolerance, $65 \%$ of the pre-diabetic patients and $78 \%$ of the type 2 diabetic patients , $\mathrm{p}<0.001$. in regards to the risk factor as age, gender, BMI, high sensitive CRP and HOMA-IR both pre-diabetes and type 2 diabetes had relation with OSA, odds ratios 3.18 (95\% CI 1.00, 10.07), $\mathrm{p}=0.049$ and $4.17(1.09,15.88), \mathrm{p}=0.036$, respectively.

A round $(31 \%)$ of patients had mild OSA, $(13 \%)$ moderate OSA, and (18\%) severe OSA. The prevalence was higher in men $(81 \%)$ than in women $(55 \%), p=0.006$, with the severity 
South American Journal of Public Health

Special Edition May 2016

of OSA more observed in men than women, also prevalence of OSA was significantly higher among postmenopausal than premenopausal women $\mathrm{p}<0.001$.

A (29\%) subjects had NGT, (42\%) preDM and (29\%) T2DM. in patients with NGT 33\% had OSA, while $67 \%$ of the preDM patients and $78 \%$ of the T2DM patients had OSA, $\mathrm{p}=$ 0.001 and $\mathrm{p}<0.001$, respectively.

In a crude logistic regression model subjects with preDM and T2DM had approximately 4and 6-fold increased odds of OSA compared with the non-diabetic group The odds of OSA in preDM and T2DM were evaluated after monitor gender, age and BMI, statistically significant. Finally, both preDM and T2DM were associated with higher odds of OSA with more assessment for HOMA-IR and high sensitive CRP strong factor as Gender 4.2 (1.2, $14.4)$ and age $1.15(1.08,1.21)$ were both having OSA with Ors $(95 \% \mathrm{CI})$ categorical variable Glucose tolerance was replaced with $\mathrm{HbAlc}$ in supplementary logistic regression analyses. $\mathrm{HbA} 1 \mathrm{c}$ was not significantly associated with OSA, odds ratio $(95 \% \mathrm{CI}) 1.29(0.79,2.12, \mathrm{p}=$ $0.314)$.

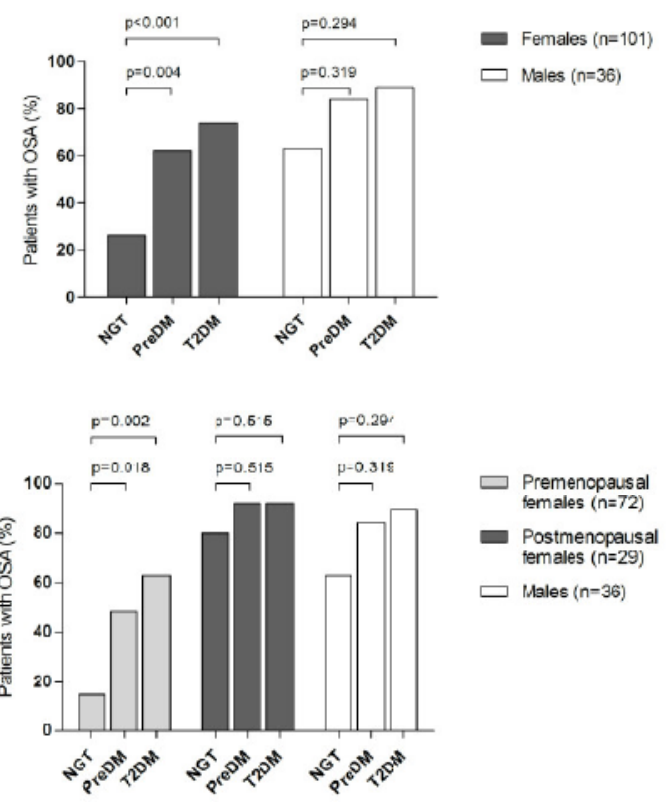

\section{Discussion}

extremely obese patients in This study demonstrates that type 2 diabetes and prediabetes have higher odds of OSA, even after taking age, gender, overall obesity (BMI), insulin resistance, inflammation, hypertension, smoking, alcohol consumption and medication as a risk

\section{Conclusion}

By the end of study we have observe that preDM and T2DM are associated with OSA in extremely obese subjects. This findings support the recommendations from the International Diabetes Federation (IDF) which suggest that subjects with T2DM should be screened for OSA .

\section{References}

[1.] Type 2 diabetes and pre-diabetes are associated with obstructive sleep apnea in extremely obese subjects Jan Magnus Fredheim 12*, Jan Rollheim1, Torbjørn Omland3, Dag Hofsø1, Jo Røislien [2.] Type 2 diabetes and pre-diabetes are associated with obstructive sleep apnea in extremely obese subjects: a cross-sectional study. Fredheim JM1, Rollheim J, Omland T, Hofsø D, Røislien J, Vegsgaard K, Hjelmesæth J 
South American Journal of Public Health Special Edition May 2016

[3.] Young T, Palta M, Dempsey J, Skatrud J, Weber S, Badr S: The occurrence of sleep-disordered breathing among middle-aged adults 